\title{
Peran Guru Pendidikan Jasmani Olahraga dan Kesehatan (PJOK) dalam Kegiatan Pelaksanaan Usaha Kesehatan Sekolah (UKS) Di Smk Negeri Se-Kabupaten Bengkulu Utara
}

\section{The Role of Sports and Health Physical Education Teachers in School Health Business Implementation Activities at All Vocationl High School in North Bengkulu Regency}

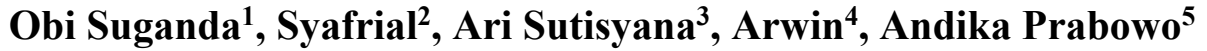 \\ ${ }^{12345}$ Pendidikan Jasmani, Universitas Bengkulu, Jl. WR Supratman Kandang Limun, Bengkulu, \\ 3871A, Indonesia
}

\begin{abstract}
Abstrak
Penelitian ini bertujuan untuk mengetahui seberapa besar peran guru pendidikan jasmani olahraga dan kesehatan dalam Kegiatan pelaksanaan Usaha Kesehatan Sekolah di SMK Negeri se-Kabupaten Bengkulu Utara. Jenis penelitian ini adalah penelitian deskriptif kualitatif. Desain yang digunakan adalah survei dengan teknik pengumpulan data menggunakan angket tertutup. Subjek dalam penelitian ini adalah guru PJOK di SMK Negeri se-Kabupaten Bengkulu Utara yang berjumlah 5 orang guru, siswa kelas I 57 orang dan penjaga UKS 3 orang. Analisis data menggunakan analisis deskriptif yang dituangkan dalam bentuk persentase. Hasil penelitian menunjukkan bahwa peran guru PJOK dalam Kegiatan pelaksanaan Usaha Kesehatan Sekolah di SMK Negeri seKabupaten Bengkulu Utara yaitu hasil dari angket untuk guru PJOK $(75.38 \%)$ kategori tinggi, hasil angket untuk siswa (83.18\%) kategori sangat tinggi, dan angket untuk penjaga UKS (93.33\%) kategori sangat tinggi
\end{abstract}

Kata kunci: Guru, PJOK, Usaha Kesehatan Sekolah.

\section{Abstract}

This study aimed to find out how much the Sport and Health Physical Education Teachers' role in the implementation of the Program School Health in north Bengkulu vocational high school. This research was designed as descriptive qualitative research. The design used the survey technique to collect data using a closed questionnaire. The subjects of this study were 5 people PJOK teachers of North Bengkulu regency Vocational High School, students grade one as much as 57 people and 3 people of medical examiner. Data analysis used a descriptive analysis that was calculating using percentage. The result of this study showed that the role of Sport and Health Physical education Teachers in the implementation of Program School Health in north Bengkulu vocational high school which was from the PJOK teachers (75.38\%) was high category, from the students (83.18\%) was very high category, and from the medical examiner $(93,33 \%)$ was very high category.

Keywords: Physical education sports and health, School health, Teacher, 


\section{PENDAHULUAN}

Usaha Kesehatan Sekolah merupakan wahana pembelajaran untuk meningkat kemampuan hidup sehat serta membentuk perilaku sehat anak usia sekolah yang sedang duduk dibangku sekolah hingga penguruan tinggi. Tujuan program UKS adalah untuk meningkatkan kemampuan hidup sehat dan derajat kesehatan siswa serta mewujudkan lingkungan yang sehat, sehingga memungkinkan pertumbuh kembang secara harmonis dan optimal dalam rangka pembentukan manusia Indonesia seutuhnya.

Salah satu rantai untuk meningkatkan derajat kesehatan penduduk adalah dengan melakukan pembinaan dan pengembangan kesehatan peserta didik melalui usaha kesehatan sekolah (UKS) karena usaha kesehatan sekolah (UKS) juga merupakan wahana untuk mewujudkan derajat kesehatan sedini mungkin (Trishandra, 2019). Pendidikan kesehatan memiliki tujuan tertentu dalam pelaksanaannya. Menurut Undang-Undang Kesehatan No. 23 Tahun 1992 bahwa tujuan pendidikan kesehatan adalah untuk meningkatkan kemampuan masyarakat dalam memelihara dan meningkatkan derajat kesehatan, dengan menjalankan program khusus seperti: pencegahan penyakit menular, kesehatan lingkungan, memperhatikan gizi masyarakat, pelayanan kesehatan, dan meningkatkan kualitas fisik, mental maupun sosial sehingga masyarkat produktif secara ekonomi dan sosial (Sari, 2013). Berdasarkan pernyataan tersebut dapat dipahami bahwakesehatan sekolah sangat penting diterapkan disekolah sebab pada masa sekolah adalah masa pertumbuhan anak, melalui usaha kesehatan sekolah perserta didik bisa membentuk prilaku hidup yang sehat dari usia sekolah sampai perguruan tinggi. Usaha kesehatan sekolah berguna untuk meningkatkan dan menjaga kesehatan siswa pada saat disekolah, sehingga perserta didik bisa terhindar dari berbagai penyakit yang ada dilingkungan sekolah.

Guru adalah sebutan suatu jabatan, posisi dan profesi bagi seseorang yang mengabdi pada dirinya sendiri di bidang pendidikan melalui interaksi secara terpola, formal dan sistematis.Keberadaan Undang-Undang Nomor 14 Tahun 2005 tentang Guru dan Dosen harus mampu melakukan upaya meningkatkan kualitas masyarakat Indonesia yang beriman, bertaqwa, dan memiliki ahlak yang mulia serta dapat menguasai ilmu pengetahuan, ilmu teknologi, dan seni barulah 
yang disebut dengan mencerdaskan kehidupan bangsa sudah tercapai (Mulyani, 2015).

Pendidikan jasmani adalah suatu proses mendidik seseorang sebagai individu atau anggota masyarakat yang dilaksanakan secara sadar dan sistematis melalui berbagai kegiatan jasmani untuk memperoleh pertumbuhan jasmani, kesehatan dan kesegaran jasmani, kemampuan dan keterampilan, kecerdasan dan perkembangan karakter yang harmonis dan kepribadian dalam rangka membentuk manusia indonesia yang berkualitas (Nopiyanto \& Raibowo, 2019). Istilah pendidikan jasmani secara eksplisit dibedakan dari olahraga. Dalam arti sempit olahraga diidentikkan dengan gerak badan (Arifin, 2017).

Peran profesional guru PJOK dalam pembelajaran pendidikan jasmani menjadi sangat penting (Raibowo et al., 2019; Saputra et al., 2021). Peranan guru pendidikan jasmani dalam melaksanakan program UKS meliputi menanamkan kebiasaan sehat pada siswanya, memeriksa dan memantau kebersihan diri dan lingkungan, mengenali kelainan siswa yang mungkin ada (jasmani dan rohani), membina kebugaran jasmani, membimbing siswa agar terampil dan efektif untuk segala gerakan ke semua aktivitasnya, termasuk menumbuhkan bakat di bidang olahraga, menjalankan pertolongan pertama dan pengobatan ringan sesuai kemampuannya dan jika perlu mengirimkannya ke poliklinik terdekat, mengenali tanda-tanda penyakit menular dan masalah serta tindakan selanjutnya (misalnya melarang siswa yang menderita cacar air, campak, pneumonia rejan, gondongan dan lain-lain, masuk sekolah), menjadi panutan bagi siswanya, mencatat kegiatan UKS, membantu petugas kesehatan dalam menjalankan tugasnya di sekolah (Apriani \& Gazali, 2018).

Setelah penulis melakukan observasi di SMK Negeri Kabupaten Bengkulu Utara antara lain: SMK Negeri 04 Bengkulu Utara, SMK Negeri 05 Bengkulu Utara dan SMK Negeri 10 Bengkulu Utara penulis menemukan beberapa Masalah. Kegiatan pelaksanaan UKS di SMK Negeri Se Kabupaten Bengkulu Utara kendala yang terjadi program UKS jarang dilaksanakan, apabila ada siswa yang sakit di sekolah maka siswa yang sakit biasanya diantar pulang ke rumah dan diserahkan kepada orang tua siswa. Serta kondisi ruangan uks yang belum memadai dan obat-obatan yang masih sedikit pernyataan ini bisa dilihat dari 
kondisi ruangan atau bagunan UKS yang masih terbilang kurang bagus masih banyak tembok-tembok retak dan tidak menarik untuk dilihat. Tidak tersedianya dana UKS yang memadai maka obat-obatan dan alat-alat medis yang ada di UKS pun masih kurang lengkap dan obat di UKS sudah banyak yang kadaluwarsa pihak sekolah hanya menyiapkan beberapa macam obat-obatan saja sehingga jika ada siswa yang terkena sakit atau penyakit pada saat di sekolah kurang mendapatkan penanganan dari pihak UKS yang sering terjadi hanya sesama siswa yang mengobati hal itu di akbiatkan pelayanan UKS tidak berjalan dengan baik

\section{METODE}

Penelitian yang dilakukan dalam penelitian ini adalah penelitian kualitatif. Menurut (Sugiyono, 2020) penelitian kualitatif adalah penelitian yang banyak di gunakan dalam penelitian sosial. Peneliti menggunakan pendekatan naturalistik untuk memahami fenomena tertentu. Penelitian yang menggunakan pendekatan kualitatif pada prinsipnya ingin menjelaskan, mendeskripsikan secara kritis atau mengambarkan suatu penomena, suatu kejadian atau pristiwa interaksi sosial dalam masyarakat untuk mencari dan menemukan makna dalam konteks nyata (natural setting). Metode pengumpulan data yang digunakan Metode angket tertutup, metode ini dilakukan dengan cara memberikan beberapa pertanyaan tertulis kepada reponden untuk dijawabnya (Sugiyono, 2020).

Dalam penelitian ini menggunakan instrumen angket digunakan untuk mengetahui peran guru pendidikan jasmani olahraga dan kesehatan (PJOK) dalam kegiatan pelaksanaan usaha kesehatan sekolah (UKS) di SMK Negeri Se Kabupaten Bengkulu Utara. Penelitian menggunakan sekala guttmann dengan 2 alternatif jawaban untuk menghitung skor pada masing-masing jawaban. Angket digunakan untuk menganalisis peran guru pendidikan jasmani olahraga dan kesehatan (PJOK) dalam kegiatan pelaksanaan usaha kesehatan sekolah angket diisi oleh 5 guru pjok, 3 penjaga UKS. Bentuk setiap angket berbeda untuk mengumpulkan data tentang evaluasi berupa masukan, komentar, kritik dan saran dari para guru pjok dan penjaga UKS. Selain itu, instrumen yang sudah divalidasi oleh ahli akan dibagikan kepada siswa dengan menggunakan angket yang diberikan kepada 57 siswa. 
Teknik analisis data adalah proses mencari dan menyusun secara sistematis data yang diperoleh dari hasil angket, catatan lapangan, dan dokumentasi, dengan mengorganisasikan data kedalam kategori, menjabarkan kedalam unit-unit, menyusun dalam pola, memilih mana yang penting, dan akan dipelajari, dan membuat kesimpulan sehingga mudah dipahami oleh diri sendiri dan orang lain. Pengolahan dan analisis data menggunakan analisis deskriptif yang dilakukan untuk melihat dan mengidentifikasi peran guru pendidikan jasmani olahraga dan kesehatan (PJOK) dalam kegiatan pelaksanaan usaha kesehatan sekolah (UKS) di SMK Negeri Se-Kabupaten Bengkulu Utara.

Rumus mengolah data deskriptif kualitatif yang digunakan (Kamelta, 2013) adalah sebagai berikut:

$$
P=\frac{F}{N} \times 100 \%
$$

\section{Keterangan:}

P: Persentase jawaban.

F: Frekuensi jawaban responden.

$\mathrm{N}$ : Total frekuensi

\section{HASIL}

Berdasarkan data yang diperoleh dari hasil penelitian yaitu menyebarkan angket tanggapan maka disajikan hasil analisis data sebagai berikut:

Tabel 1. Data Hasil Persentase Kueioner Guru PJOK

\begin{tabular}{cccccc}
\hline \multirow{2}{*}{ No } & \multirow{2}{*}{ Nama Sekolah } & \multicolumn{2}{c}{ Angket Guru } & \multicolumn{2}{c}{ Persentase } \\
\cline { 3 - 6 } & & Ya & Tidak & $\%$ & $\%$ \\
\hline 1 & SMK Negeri 04 B.U & 31 & 6 & 83,78 & 16,22 \\
2 & SMK Negeri 05 B.U & 74 & 37 & 66,67 & 33,33 \\
3 & SMK Negeri 10 B.U & 28 & 9 & 75,68 & 24,32 \\
\hline & Jumlah & 133 & 52 & 226,13 & 73,87 \\
\hline & Rata-Rata & 44,33 & 17,33 & 75,38 & 24,62 \\
\hline
\end{tabular}


Obi Suganda, Syafrial, Ari Sutisyana, Arwin, Andika Prabowo

Peran Guru PJOK dalam Kegiatan Pelaksanaan Usaha Kesehatan Sekolah (UKS) di SMK Negeri se-Kabupaten Bengkulu Utara

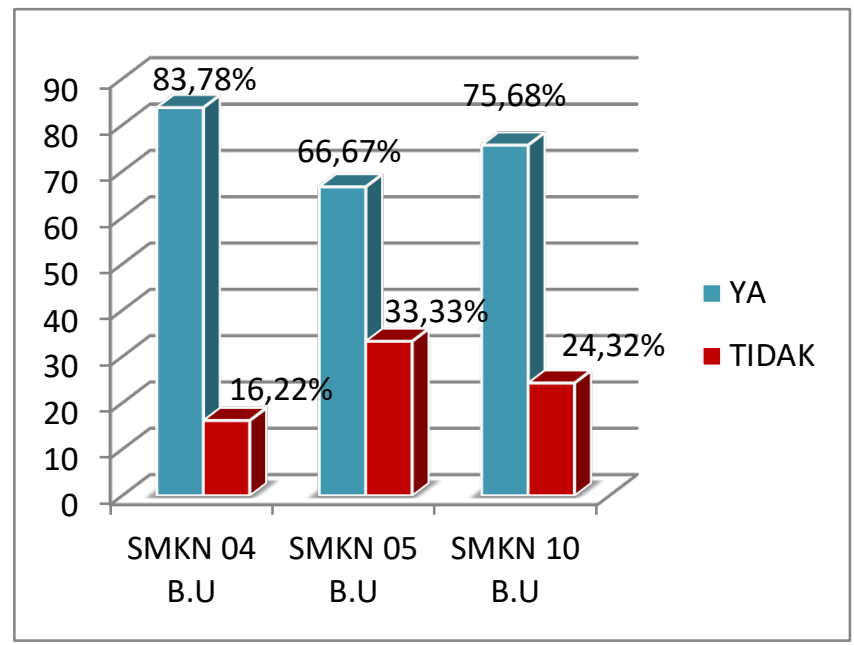

Gambar 1. Diagram Persentase Guru PJOK

Tabel 2. Data Hasil Persentase Kuesioner Siswa

\begin{tabular}{cccccc}
\hline \multirow{2}{*}{ No } & \multirow{2}{*}{ Nama Sekolah } & \multicolumn{2}{c}{ Angket Siswa } & \multicolumn{2}{c}{ Persentase } \\
\cline { 3 - 6 } & & Ya & Tidak & $\%$ & $\%$ \\
\hline 1 & SMK Negeri 04 B.U & 271 & 69 & 79,71 & 20,29 \\
2 & SMK Negeri 05 B.U & 324 & 76 & 81 & 19 \\
3 & SMK Negeri 10 B.U & 302 & 38 & 88,82 & 11,18 \\
\hline & Jumlah & 897 & 183 & 249,53 & 50,47 \\
\hline & Rata-Rata & 299 & 61 & 83,18 & 16,82 \\
\hline
\end{tabular}

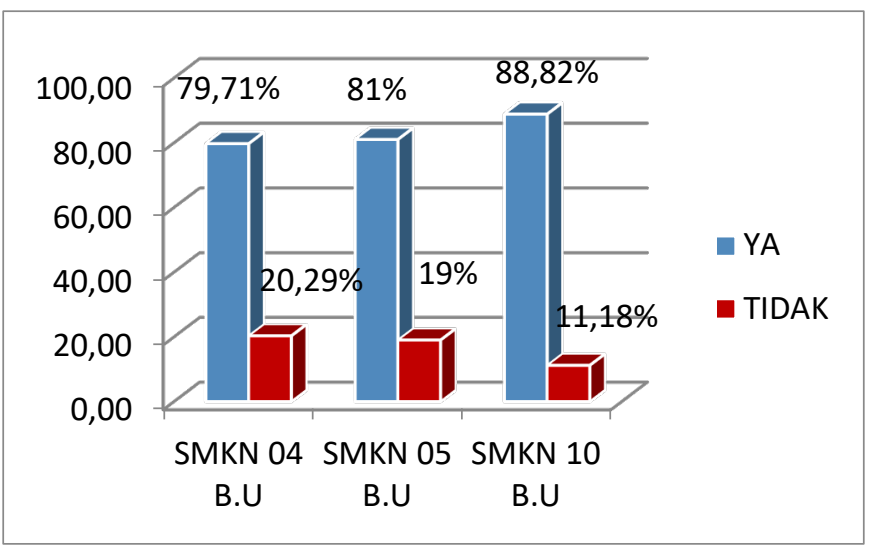

Gambar 2. Diagram Persentase Siswa

Tabel 3. Data Hasil Persentase Kuesioner Penjaga UKS

\begin{tabular}{cccccc}
\hline \multirow{2}{*}{ No } & \multirow{2}{*}{ Nama Sekolah } & \multicolumn{2}{c}{ Angket } & \multicolumn{2}{c}{ Persentase } \\
\cline { 3 - 6 } & & Ya & Tidak & $\%$ & $\%$ \\
\hline 1 & SMK Negeri 04 B.U & 19 & 1 & 95 & 5 \\
2 & SMK Negeri 05 B.U & 19 & 1 & 95 & 5 \\
3 & SMK Negeri 10 B.U & 18 & 2 & 90 & 10 \\
\hline & Jumlah & 56 & 4 & 280 & 20 \\
\hline & Rata-Rata & 18,67 & 1,33 & 93,33 & 6,67
\end{tabular}




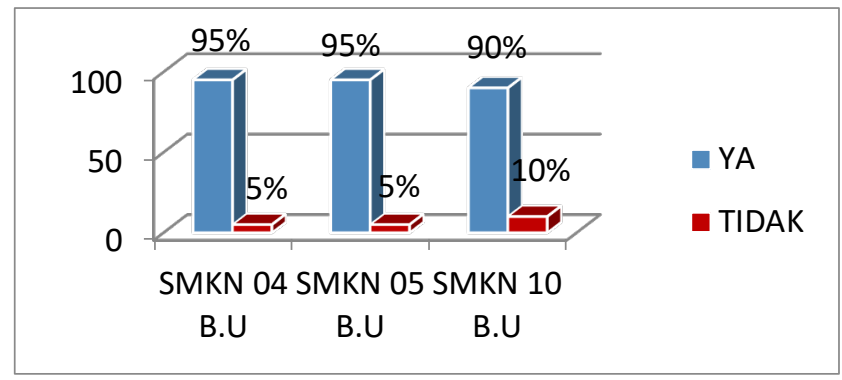

Gambar 2. Diagram Persentase Penjaga UKS

\section{PEMBAHASAN}

Berdasarkan hasil penelitian, menunjukkan bahwa peran guru PJOK dalam kegiatan pelaksanaan UKS di SMK Negeri se-Kabupaten Bengkulu Utara diantara lain : SMK N 04 Bengkulu Utara, SMK N 05 Bengkulu Utara, SMK N 10 Bengkulu Utaraberada pada kategori berperan hal ini dikarenakan sebagian besar guru PJOK di SMK Negeri se-Kabupaten Bengkulu Utara sudah melakukan tanggung jawab mereka, seperti: (1) Pendidikan Kesehatan; (2) Pelayanan Kesehatan; (3) Pembinaan Kesehatan

Peran guru PJOK dalam kegiatan UKS di SMK Negeri Kabupaten Bengkulu Utara sudah berperan dalam pelaksanaan UKS. Seperti turut andil dalam pelayanan kesehatan, pendidikan kesehatan, dan pembinaan kesehatan. Contohnya jika ada siswa yang sakit atau mengalami kecelakaan, guru dengan tanggap memberikan pertolongan pertama kemudian membawa ke UKS dan jika parah langsung dirujuk ke klinik atau klinik terdekat. Kemudian menerapkan kegiatan gotong-royong disekolah sebagai langkah awal untuk menjaga kebersihan sekolah. Guru PJOK adalah salah satu warga sekolah yang memiliki peran vital dalam membagikan pemahaman mengenai kesiapsiagaan dalam menjaga kesehatan kepada peserta didik (Nopiyanto et al., 2021). Pentingnya kualitas tenaga pendidik dan sarana prasarana pendukung untuk mewujudkan tujuan pendidikan, khususnya pada pendidikan jasmani olahraga dan kesehatan yang memiliki peran penting dalam tumbuh kembang peserta didik harus benar-benar diperhatikan (Raibowo et al., 2021)

Pendidikan kesehatan diberikan kepada peserta didik, baik sebagai bagian dari kurikulum pelajaran di kelas maupun kegiatan ekstrakurikuler (Kurnia,2017). Berdasarkan hasil penelitian yang telah dilakukan dengan menggunakan metode 
observasi dan angket/kuesioner mengenai pendidikan kesehatan bahwa pendidikan kesehatan yang berlangsung di SMK Negeri Kabupaten Bengkulu Utara selalu diterapkan oleh guru PJOK seperti guru PJOK memberikan penjelasan atau menjelaskan tujuan dan manfaat adanya UKS di sekolah kepada siswa dengan demikian siswa dapat mengetahui fungsi dan tujuan UKS.

Pelaksanaan pelayanan kesehatan sekolah dilakukan secara komprehensif, yaitu bersifat menyeluruh (Kurnia, 2017). Kegiatannya ditujukan pada peningkatan kesehatan dan melakukan tindakan pencegahan terhadap serangan penyakit. Berdasarkan hasil penelitian yang telah dilakukan dengan menggunakan metode observasi dan angket/kuesioner mengenai pelayanan kesehatan bahwa pelayanan kesehatan yang berlangsung di SMK Negeri Kabupaten Bengkulu Utara selalu dilakukan oleh guru PJOK seperti melakukan pertolongan pertama pada siswa yang mengalami kecelakaan, pingsan, dan cedera, ikut serta dalam menyusun program kegiatan UKS, mengarahkan program UKS agar berjalan sebagaimana mestinya, dan mengevaluasi pelaksanaan UKS. Dengan demikian guru PJOK selalu ikut serta dalam memberikan pelayanan kesehatan dalam bentuk apapun sesuai dengan program kegiatan UKS dan di SMK Negeri Kabupaten Bengkulu Utara sudah memiliki ruangan UKS tersendiri dan kondisi ruangan UKS sudah baik, bersih, dan bangunannya pun sudah tembok semen permanen sehingga apabila ada siswa yang sakit tidak dibawa ke kantor guru, serta kelengkapan obat dan alat-alat UKS di SMK Negeri Kabupaten Bengkulu Utara sudah cukup lengkap.

Pembinaan lingkungan hidup sehat adalah upaya untuk mewujudkan lingkungan sekolah yang bersih dan sehat (Kurnia, 2017). Maka berdasarkan hasil penelitian yang telah dilakukan dengan menggunakan metode observasi dan angket/kuesioner mengenai pembinaan kesehatan bahwa pembinaan kesehatan yang berlangsung di SMK Negeri Kabupaten Bengkulu Utara selalu dilakukan oleh guru PJOK seperti mengadakan kebersihan sekolah. Dengan demikian siswa dan guru bersama-sama bersinergi untuk menjaga kebersihan diri sendiri sehingga kebersihan dan kesehatan lingkungan sekolah bisa terjaga. 


\section{KESIMPULAN}

Berdasarkan hasil penelitian yang telah diuraikan pada babsebelumnya, didapatkan hasil bahwa peran guru pendidikan jasmani olahraga dan kesehatan dalam kegiatan pelaksanaan usaha kesehatan sekolah di SMK Negeri se-Kabupaten Bengkulu Utara rata-rata berkategori tinggi.

\section{REFERENSI}

Akbar, S. \& Sriwiyana, H. (2010). Pengembangan Kurikulum Danpembelajaran Ilmu Pengetahuan Sosial (Ips). Yogyakarta.

Arifin, S. (2017). Peran Guru Pendidikan Jasmani Dalam Pembentukan Pendidikan Karakter Peserta Didik Syamsul Arifin. Jurnal Multilateral, 16(1), 78-92.

Mari, A. Yusuf. (2014). Metode Penelitian Kuantitatif, Kualitatif, Dan Penelitian Gabungan. Jakarta:Kencana, 6(1), 338. Https://Doi.Org/10.21831/Jk.V6i1.14456

Mulyani, F. (2015). Konsep Kompetensi Guru Dalam Undang-Undang Nomor 14 Tahun 2005 Tentang Guru Dan Dosen ( Kajian Ilmu Pendidikan Islam ). Jurna Pendidikan Universitas Garut, 03(01), 1-8.

Nopiyanto, Y. E., Raibowo, S., \& Prabowo, A. (2021). Peran Guru Penjas Dalam Kesiapsiagaan Bencana Alam Gempa Bumi Di Sekolah Dasar Kecamatan Taba Atas. Jurnal Pendidikan Kesehatan Rekreasi, 7(2), 295-303. Https://Doi.Org/10.5281/Zenodo.4896277

Raibowo, S., Nopiyanto, Y. E., \& Muna, M. K. (2019). Pemahaman Guru Pjok Tentang Standar Kompetensi Profesional. Journal Of Sport Education (Jope), 2(1), 11. Https://Doi.Org/10.31258/Jope.2.1.10-15

Raibowo, S., Nopiyanto, Y. E., Sutisyana, A., \& Prabowo, A. (2021). Workshop Pembuatan Bahan Ajar Kesiapsiagaan Bencana Alam Dalam Bentuk Multimedia Interaktif Bagi Guru Pendidikan Jasmani. Gervasi: Jurnal Pengabdian Kepada Masyarakat, 5(2), 218-230. Https://Doi.Org/10.31571/Gervasi.V5i2.2180

Saputra, B. S., Syafrial, S., \& Raibowo, S. (2021). Persepsi Kepala Sekolah Dan Guru Terhadap Kompetensi Guru Pjok Sekolah Menengah Pertama Di Kecamatan Arga Makmur. Sport Gymnastics: Jurnal Ilmiah Pendidikan Jasmani, 2(1), 70-78. Https://Doi.Org/10.33369/Gymnastics.V2i1.14774

Sari, I. P. T. P. (2013). Pendidikan Kesehatan Sekolah Sebagai Proses Perubahan Perilaku Siswa. Jurnal Pendidikan Jasmani Olahraga, 9(November), 141147.

Sugiyono. (2009). Metode Penelitian Pendidikan, Pendekatan Kuantitatif, Kualitatif Dan $R \& D$. Alfabeta.

Sugiyono. (2012). Metode Penelitian Kuantitatif Kualitatif Dan R\&D. Alfabeta.

Trishandra, J. (2019). Tinjauan Pelaksanaan Usaha Kesehatan Sekolah Di Sd Negeri 159/Iii Semumu Kecamatan Depati Vii Kabupaten Kerinci Jonika. Ensiklopedia Of Jurnal, 8(5), 55. 